\title{
The Phenix Detector Magnet Subsystem
}

\author{
Robert M. Yamamoto, Joel M. Bowers, Arthur R. Harvey, Robert H. Holmes, \\ Glen F. James, Marcus A. Libkind, Richard W. Martin, Larry E. Mullins, James \\ H. Thomas, Winston J. Wong, (LLNL), Samuel H. Aronson, Stephen A. Kahn, \\ Peter J. Kroon, Thomas J. Shea, (BNL), Ross D. Schlueter, (LBL), and \\ Walter E. Sondheim, (LANL)
}

This paper was prepared for submittal to the Fourteenth International Conference on Magnet Technology Tampere, Finland

June 11-16, 1995

May 19, 1995
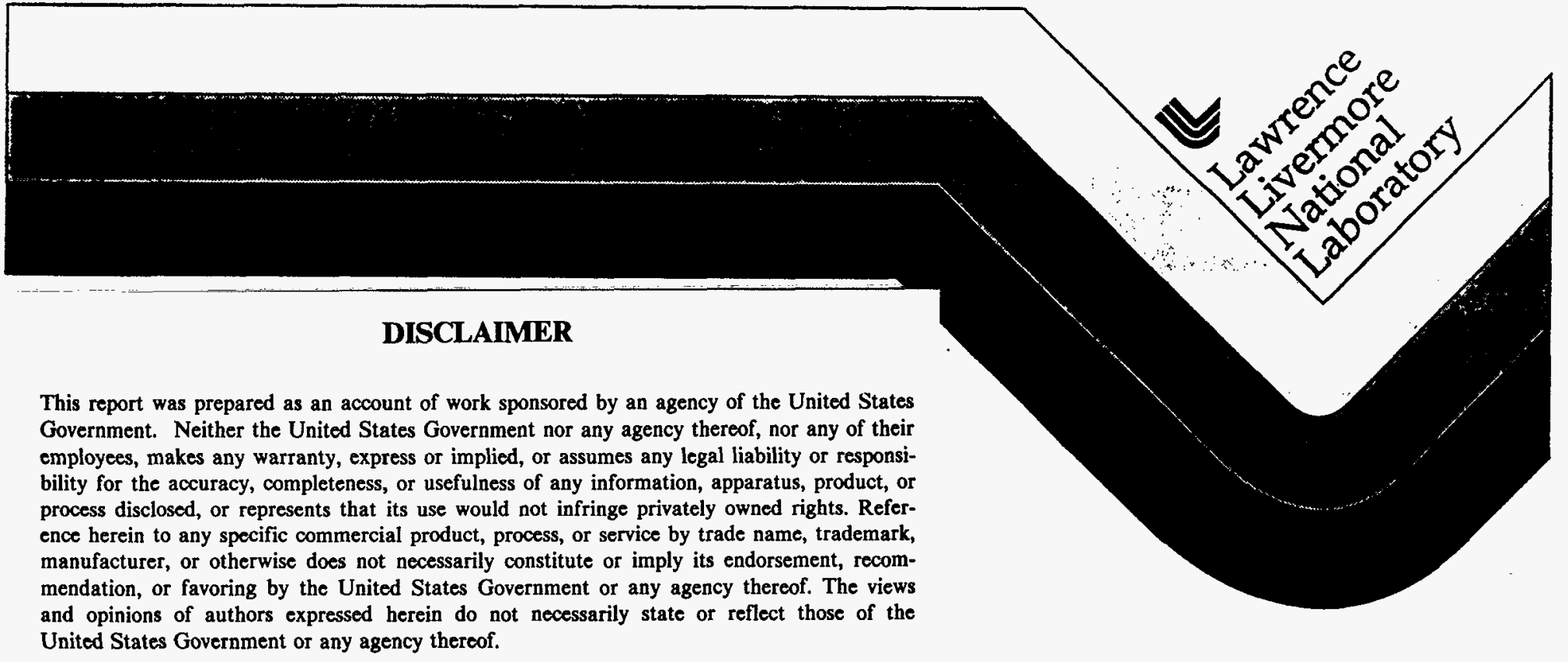

United States Government or any agency thereof. 


\title{
The PHENIX Detector Magnet Subsystem
}

\author{
Robert M. Yamamoto, Joel M. Bowers, Arthur R. Harvey, Robert H. Holmes, Glen F. James, \\ Marcus A. Libkind, Richard W. Martin, Larry E. Mullins, James H. Thomas, Winston J. Wong \\ Lawrence Livermore National Laboratory, Livermore, CA 94550
}

Samuel H. Aronson, Stephen A. Kahn, Peter J. Kroon, Thomas J. Shea Brookhaven National Laboratory, Upton, NY 11973

Ross D. Schlueter

Lawrence Berkeley Laboratory, Berkeley, CA 94720

Walter E. Sondheim

Los Alamos National Laboratory, Los Alamos, NM 87545

\begin{abstract}
The PHENIX [Photon Electron New Heavy Ion R.periment] Detector is one of two large detectors presently under construction for RHIC (Relativistic Heavy Ion Collider) located at Brookhaven National Laboratory. Its primary goal is to detect a new phase of matter; the quark-gluon plasma. In order to achieve this objective, the PEIENIX Detector utilizes a complex magnet subsystem which is comprised of two large maguets identified as the Central Magnet (CM) and the Muon Marenet (MM). Muon Identifier steel is also included as part of this package. The entire magnet subsystem stands over 10 meters tall and weighs in excess of 1900 tons (see Fig. 1). Magnet size alone provided many technical challenges throughont the design and fabrication of the project. In addition, interaction with foreign collaborators provided the authors with new areas to address and problems to solve. Ruatian collaborators would fabricate a large fraction of the steel required and Japanese collaborators would supply the first coil. This paper will describe the overall design of the PEINIX maget aubsystem and discuss its present fabrication status.
\end{abstract}

\section{MAGNET DESIGN \& DEVELOPMENT}

The top level magnetic design requirements for the PHENIX magnet subsystem were developed jointly by groups form Brookhaven (BNL), Los Alamos (LANL), Oak Ridge (ORNL), Lawrence Berkeley (LBL), and Lawrence Livermore (LLNL) National Laboratories. This collaboration started discussing the requirements in late 1991/early 1992. Several reports discussing these requirements were written including a preliminary design report [1] and a conceptual design report [2]. Much iteration took place between the physics requirements desired and what engineering could realistically deliver.

One of the key engineering design studies made early on during the conceptual design phase of the project was to decide whether superconducting or resistive coils would be employed. Requirements considered included:

- For the Central Magnet (CM), an integrated field strength $\int \mathrm{B}$-dl of 0.7 to 1.0 Tesla-meter.

- Provide unobstructed aperture for the CM such that particle detector coverage was maximized.

- For the Muon Magnet (MM), an integrated field strength of $\int \mathrm{Br} \cdot \mathrm{dl}$ of 0.72 Tesla-meter (along $15^{\circ}$ line from beam axis).

This work was performed under the auspices of the U.S. Department of Energy by Lawrence Livermore National Laboratory under contract No. W-7405-ENG-48. and supported in pare by Brookhaven National Laboratory under contract no. DEAC02-76CH00016.

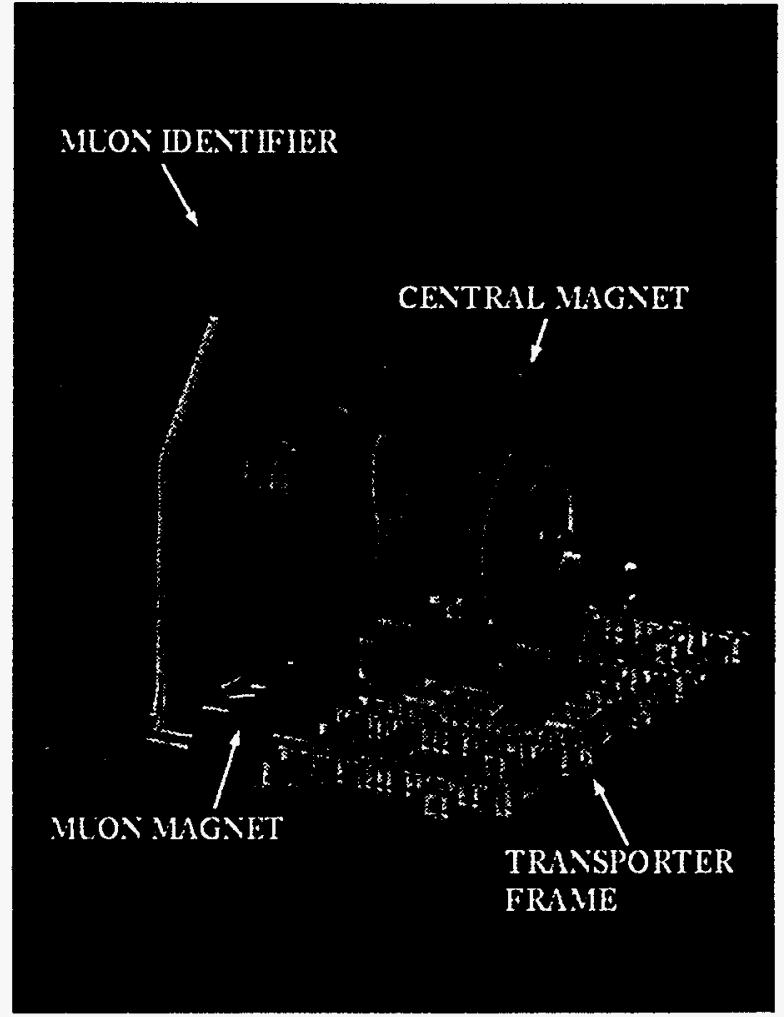

Fig. 1. The PHENIX Detector Magnet Subsystem.

The superconducting version of the coils would utilize standard $\mathrm{Nb}-\mathrm{Ti}$ superconductor in an Aluminum stabilizer. The conductor would be wound on an aluminum bobbin and indirectly cooled via liquid helium flowing through a tube welded to the bobbin. The resistive coil option would employ square hollow copper conductor, water cooled, wrapped with conventional mylar and dacron insulation and vacuum impregnated.

In general the superconducting version required more ampere-turns than the resistive coil option, primarily due to the increased space required for the cryostat. This reduced the cross-sectional area of the steel and increased saturation affects. Because of this, significantly more ampere-turns were required in the superconducting version to achieve the same integrated field strengths.

Choice of technology included optimization of a number of parameters including initial cost, schedule, performance. 


\section{DISCLAIMER}

Portions of this document may be illegible in electronic image products. Images are produced from the best available original document. 
tochnical risk, upgrade capability and operational costs. The final resolution was that resistive coils would be employed for both the Central Magnet and Muon Magnet.

\section{MAGNET SYSTEM OVERVIEW}

The Central Magnet stands approximately 9.5 meters tall and weighs nearly 500 tons. It employs an axial field energized by two pairs of concentric coils, the Outer and Inner coils. These coils are recessed into the faces of the two steel poles. This magnet provides a field around the interaction vertex that is parallel to the incoming beam and is used for momentum analysis of charged particles. The gap between the pole tips is $120 \mathrm{~cm}$, which allows room for the inner silicon detectors and the inner drift chambers.

The Muon Magnet stands approximately 10.5 meters tall and weighs more than 400 tons. It utilizes two cylindrical coils to produce a radial magnetic field for the analysis of muons. The coils are wound around the large end of the tapered steel piston. The flux generated by the coils is distributed radially to the eight lampshade panels that circumscribe the piston. A large $300 \mathrm{~mm}$ thick endplate completes the magnetic loop from the lampshades back to the piston. Fig. 2 is a quarter symmetrical magnetic flux plot showing the direction of the flux lines and the saturation affects in the steel.

The Muon Identifier Steel is comprised of 5 steel plates and resides directly behind the Muon Magnet. The first two steel plates are $100 \mathrm{~mm}$ in thickness and the last three steel plates are $200 \mathrm{~mm}$ in thickness. The plates stand approximately 10.5 meters tall and have a gap in-between them such that muon detector panels can be interleaved. Total $\mathrm{Mu}$ ID steel weight is approximately 1000 tons.

As the actual magnet design matured, the question of fabrication capability arose. In particular, the fabrication of the large steel forgings required for the Central Magnet \&

Muon Magnet. A world wide fabrication capability survey commenced to understand the limitations of steel size. This information was incorporated into the design of the magnet steel to ensure that the designed steel would not exceed world fabrication limitations. Many of the steel components would need single raw steel ingots in excess of 100 tons and the

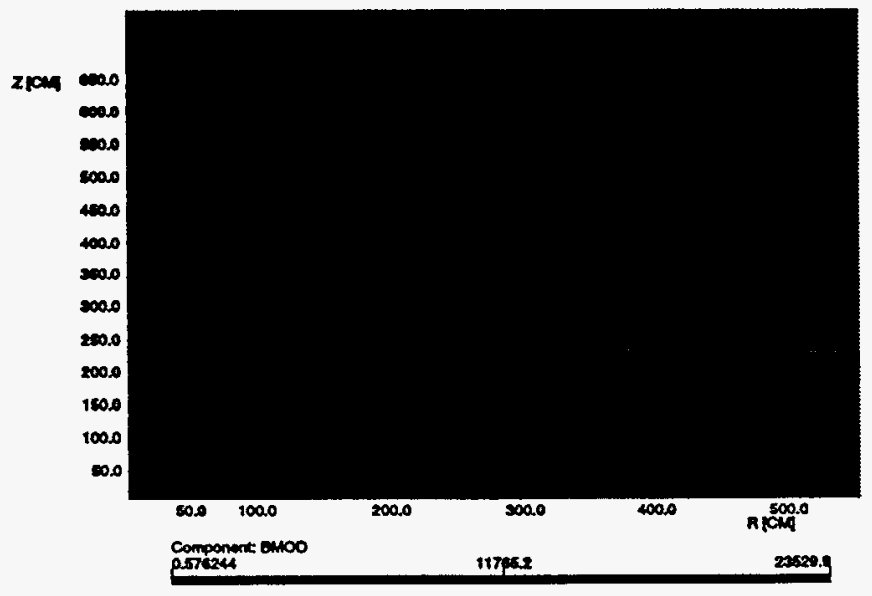

Fig. 2. Quarter symmetrical magnetic flux plot showing the direction of the flux lines and the saturation affects in the steel. design staff wanted to be certain that these large forgings could be produced.

The preliminary and detail design of the magnet subsystem which includes the $\mathrm{Mu}$ ID steel was done by the design team at LLNL. All components whether they be steel or coil related are being fabricated from "build to print" drawings (as opposed to "build to specification") generated by LINL. The only exception to this are the power supplies required to energize the coils. They are in the process of being procured by a "build to spec." that was developed and written by LLNL.

\section{STEEL DESIGN \& FABRICATION}

The Central Magnet steel structure consists of two poles, two large flux returns, and a support structure. All magnetic material is ASTM 1006, or equivalent. The large size of these poles exceeds world fabrication capacity, so each is split into three concentric parts. The outermost part, called the pole ring, has a finished weight of 60 tons and interfaces to the flux return yokes. The pole piece fits into the pole ring and weighs 61 tons. The center element of the pole, which surrounds the RHIC beam pipe, is made from thick rolled plate and weighs 7 tons. Machined circular grooves in the pole assemblies accept the Inner and Outer coils. The two poles are separated by a nominal gap of 1.2 meters, and resists an attractive force of approximately $170,000 \mathrm{lb}$. The two facing poles are magnetically and structurally tied together by two large flux retum yokes (approx. 3.2 square meters cross section), attached to the top and bottom of the poles. The large size of these return yokes dictates that they be split into smaller pieces. Each yoke subassembly consists of two pole keys and a yoke. Total weight of the each yoke subassembly is 90 tons. The entire pole assembly is supported on a rigid steel structure. This structure is designed to allow the Central Magnet to translate a short distance $(1.5 \mathrm{~m})$ along the beam axis ( $\mathrm{z}$ direction) and then move horizontally transverse to the beam ( $x$ direction) several meters into the working area of the detector hall. A transporter system consisting of Hilman rollers, hydraulic jacks, and steel plate is used to accomplish this.

The Muon Magnet steel structure consists of a large tapered iron core bolted to a flux return end plate which is 30 cm (11.81 in) in thickness. Eight trapezoidal steel plates, 8 $\mathrm{cm}$ in thickness, are arranged in an octagon pattern ("lampshade") around the iron core. These plates provide the return flux path for the muon piston magnet. The bottom three plates bolt together to form a permanent element of the overall structure. The top five plates are split across the global $Z$ axis into a permanent "teacup" section and five independently removable lampshade pieces. The tapered iron core is forged as a single piece and weighs approximately 60 tons. The end plate is constructed from three plate sections bolted together and the "lampshade" flux return is fabricated from rolled plate. All magnetic material is ASTM 1006, or equivalent. The iron core, back plate, and "lampshade" plate assemblies forms a rigid steel structure. This structure is designed to allow for access of the three sets of muon chambers that mount inside the open volume between the iron core and the "lampshade". The muon piston magnet 
assembly is a stationary structure which rests on metal shims during detector operation. Steel plates are embedded into the experimental hall floor to provide load spreading of the muon magnet into the concrete foundation.

Our Russian collaborators were extremely interested in providing the magnet steel to PHENIX as part of their "inkind" contribution to the collaboration. - A team comprised of Petersburg Nuclear Physics Institute (PNPI), the Efremov Scientific Institute and Izhora Steel Works worked closely with the magnet design team to make this desire reality. The entire magnet steel assembly, excluding the transport system, is being fabricated at Izhora Steel Works, located in the greater St. Petersburg area, Russia. The steel will be completely fabricated and preassembled in Russia prior to shipment to BNL. In this way, any modifications required to the steel found during this exercise can be done prior to shipment. This will ensure proper fitment of the components received at $\mathrm{BNL}$ and minimize onsite rework. The design accommodates shipping constraints, and allows for $100 \%$ bolt up assembly at BNL. A strict quality assurance program has be implemented in Russia to minimize risk to the program. An installation study has been performed by an experienced rigging company to determine equipment, manpower, space, time and logistics requirements such that the assembly. and installation of the magnet subsystem at BNL can be done in an efficient and cost effective manner. A contract is planned to be negotiated with Long Island Lighting Company (LILCO) for use of their docking facility at Shoreham Nuclear Power Station, which is in close proximity to BNL. This facility will be used to off load the steel components from barges as they come from Russia. The steel will then be transported over local roads using multiaxis, self jacking trailers to BNL.

The present status of the steel fabrication in Russia is that almost all of the raw ingots and forgings required for the magnet subsystem have been made. Fig. 3 shows the completed forging for the Muon Magnet piston. As can be seen, the size of this magnet is very large indeed. Another example of this is the recent production of a single rolled plate to be used as part of the Muon Magnet back plate assembly. A Russian record of 92 tons was achieved while producing this $320 \mathrm{~mm}$ thick plate. Preliminary machining of many components have started and ultrasonic inspection of the forgings and rolled plate are in progress. The present schedule shows that all steel for the Central Magnet and Muon Magnet will be completely fabricated and assembled in Russia by the end of this calendar year. Receipt of this steel at BNL will transpire shortly after this.

\section{COIL DESIGN \& FABRICATION}

The Central Magnet utilizes two coils to produce its magnetic field, the Outer Coil and the Inner Coil. The coils can be energized in parallel or in opposition to achieve the required magnetic field levels, depending on physics requirements. At this time, the Inner Coil is not required for the initial experiments that are planned to be performed and hence its production has been deferred. The design and detail drawings of the Inner Coil are complete.

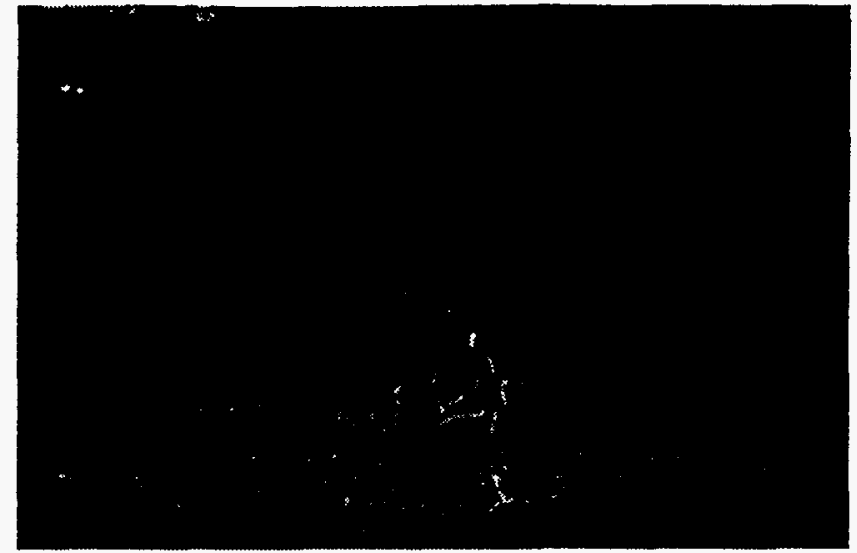

Fig. 3. Mivon Magnet piston forging at Izhora Steel, Russia. Finished weight approx. 60 tons and over 4 meters long.

The Outer Coils ( 2 required) are conceptually identical in design to the Inner Coils. They are made up of 6 identical (except for the electrical flag connections) bifilar wound double pancake coils with each double pancake assembly being individually vacuum epoxy impregnated. They have an inside diameter of $3200 \mathrm{~mm}$ (125.98 in) and a nominal outside diameter of $3729 \mathrm{~mm}$ (146.8 in). Nominal coil assembly width is $300 \mathrm{~mm}$ (11.81 in). There is a $6 \mathrm{~mm}$ clearance between the ID of the coil and the inside surface of the counterbore (to allow for coil installation onto the steel poles). The six double pancake assemblies that make up the outer coil are nested together side by side and rest on the circular counterbore machined into the iron pole pieces of the Central Magnet.

The Outer Coils have a design value of 247,500 amp-turns and utilizes a copper conductor which is $20.32 \mathrm{~mm}$ ( $0.800 \mathrm{in}$ ) square with a $12.83 \mathrm{~mm}(0.505 \mathrm{in})$ hole. The coil configuration is a 144 turn conductor package (24 turns per double pancake times 6 double pancakes). Total conductor length is 1578 meters $(5176 \mathrm{ft})$ per coil resulting in a coil weight of $4003 \mathrm{~kg}(8826 \mathrm{lbs})$. Maximum outlet water temperature rise is $45.6^{\circ} \mathrm{C}$ (inlet water thperature is $20^{\circ} \mathrm{C}$ ) which corresponds to an average condutctor temperature of $32.8^{\circ} \mathrm{C}$. Required water flow rate is 43.9 gallons/minute per coil.

The Outer Coil requires 1719 amps @ 174 volts for a power supply requirement of 300 kwatts (247,500 amp-turns) per coil. The coil can theoretically achieve 367,200 ampturns ( $48 \%$ increase) by allowing the outlet water temperature to rise to $80^{\circ} \mathrm{C}$ (vs. $45.6^{\circ} \mathrm{C}$ ) and using a power supply of 699 kwatts (2550 amps @274 volts) per coil.

The muon piston coil ( 1 required) is a bifilar wound solenoidal coil (having two layers) which will be vacuum epoxy impregnated onto its epoxy-fiberglass winding form. It is made up of two identical coils with the only difference being that one is slightly smaller in diameter than the other. Each coil is $676.4 \mathrm{~mm}$ (26.63 in) in overall length. The small coil (coil \#1) is nominally $1623.8 \mathrm{~mm}$ (63.93 in) in ID and $1740.4 \mathrm{~mm}(68.52 \mathrm{in})$ in OD. The large coil (coil \#2) is $1880.6 \mathrm{~mm}$ (74.04 in) in ID and 1997.2 mm (78.63 in) in OD.

The Muon Coil has a design value of 300,000 amp-turns. It utilizes a square, hollow, copper magnet conductor which is nominally $24.13 \mathrm{~mm}(0.95 \mathrm{in})$ square with a $15.49 \mathrm{~mm}$ 
( $0.6098 \mathrm{in})$ hole. The coil configuration is a 102 turn conductor package comprised of two layers of solenoidal type windings. Each coil has 51 turns each. Total conductor length required is 581 meters (1906 ft) for the entire two coil assembly; the small coil requires 270 meters of conductor and the large coil requires 311 meters. Overall coil assembly weight is $2047 \mathrm{~kg}$ (4514 lbs); the small coil weighs $951 \mathrm{~kg}$ (2097 lbs) and the large coil weighs $1096 \mathrm{~kg}$ (2417 lbs). Each bifilar wound conductor segment has its own individual water circuit in addition to each coil layer having its own parallel water supply giving rise to a total of 8 individual water circuits. The LCW system provides cooling water to achieve a pressure drop of 60 psig with a maximum water temperature rise of $35^{\circ} \mathrm{C}$ (inlet water temperature is $20^{\circ} \mathrm{C}$ ) which corresponds to an average conductor temperature of $25.6^{\circ} \mathrm{C}$ for the smaller coil and $27.1^{\circ} \mathrm{C}$ for the larger coil. The copper conductor will be insulated with a "half-lap" of mylar tape enclosed in a continuous dacron sheath, wound on a coil winding form, ground wrapped with wide dacron cloth tape and epoxy impregnated under vacuum in a potting mold. Both before and after vacuum impregnation, the coils will be electrically checked for shorts and hydrostatically pressure checked and flow checked through each of the 8 water circuits. Required water flow rate is approx. 67.9 gallons/minute for the entire coil assembly; $35.3 \mathrm{gpm}$ for the small coil and $32.6 \mathrm{gpm}$ for the large coil.

The Muon Coil requires 2941 amps @ 76.6 volts (35.5 volts for the small coil and 41.1 volts for the large coil) for a power supply requirement of 225 kwatts $(300,000$ ampturns). The coil can theoretically achieve 587,739 amp-turns by allowing the outlet water temperature to rise to $80^{\circ} \mathrm{C}$ (vs. approx. $34^{\circ} \mathrm{C}$ ) and using a power supply of 944 kwatts (5762 amps @ 164 volts).

The present status of the Central Magnet Outer Coil is that its fabrication is $100 \%$ complete. These coils were fabricated in entirety by the Magnet Division of the TOKIN Corporation, Sendai, Japan. Like the magnet steel, the Outer Coils are being provided as an "in-kind" contribution by our Japanese Collaborators. TOKIN Corp. has completed the final full current testing of the two coil assemblies at KEK.

All twelve double pancake assemblies have been boxed into ocean worthy wooden containers and are awaiting final shipment to BNL. They plan to arrive at BNL sometime this summer. Fabrication of the Muon Magnet Coils is planned to

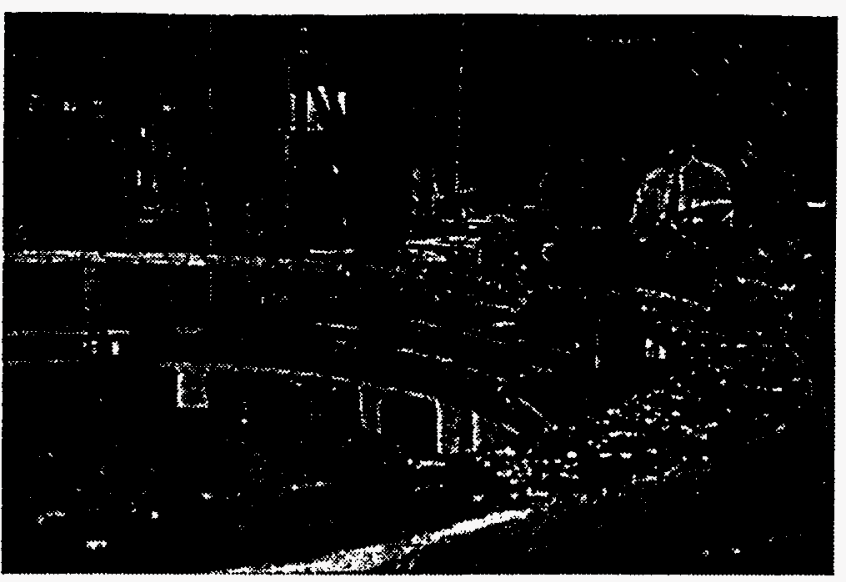

Fig. 4 Central Magnet Outer Coil double pancake assembly being prepared for electrical testing at TOKIN Corporation, Sendai, Japan.

commence shortly pending a release of funds by project management. Power Supplies for both the Central Magnet Outer Coils and the Muon Magnet Coils are out for bid and award of these supplies should also commence soon.

\section{ACKNOWLEDGMENT}

The authors wish to thank Vladimir Kashikhin, Vitaly Shangin and Yury Severgin of the Efremov Scientific Institute, St. Petersburg, Russia for all of their effort and hard work in making the fabrication of the magnet steel a complete success story. In addition, we would like to thank Kazuhiro (Banpaku) Tanaka of KEK, National Laboratory of High Energy Physics in Japan and Kazuo Katoh and Tatsuya Kuroda of the TOKIN Corporation, Japan for providing the Central Magnet Outer Coils in excellent working order. Last but not least, we would like to thank our secretary at LLNL, Sonia Haro, for providing support to this project throughout its many stages, including the myriad of foreign travel requests required during the fabrication phase of the project.

\section{REFERENCES}

[1] PHENIX Preliminary Conceptual Design Report, June, 1992.

[2] PHENIX Conceptual Design Report, January, 1993. 